КОЛОНКА ГЛАВНОГО РЕДАКТОРА

DOI: https://doi.org/10.15688/lc.jvolsu.2021.1.1

UDC 347:346.26

LBC 67.404 .91

\title{
LEGAL ADAPTATION IN THE CONTEXT OF THE IMPACT OF THE INDUSTRIAL REVOLUTION ON BUSINESS ACTIVITY AND THE KEY COMPONENTS OF THE ECOSYSTEM
}

\author{
Agnessa O. Inshakova \\ Volgograd State University, Volgograd, Russian Federation
}

\begin{abstract}
Annotation. The paper is an overview of the themes selected for the main topic of the issue, their relevance and the validity of the research conducted in the journal for the legislation and law enforcement practice in the context of the industrial revolution and the need for greening modern business. In addition, the author explains the editorial board's choice of the main topic of the next issue of the legal journal of Volgograd State University "LegalConcept = Legal paradigm" under the title "The right to protect human health and an environmentally friendly business environment". The objective need for the technology development of the intensive involvement of the potential of Russian environmental entrepreneurship in the industrial revolution processes is substantiated. The most important tasks are identified, which are addressed by the developments in the legal regulation of the digitalization processes of environmental entrepreneurship in Russia. The author lists a set of measures that, in the author's opinion, are of primary importance for ensuring these processes. It is noted that the topic proposed for development is closely related to the formation of scientific and technological foundations that ensure the economic growth and social development of the Russian Federation. The state of scientific and technological progress achieved by modern society is manifested by the widespread use of digital technologies in various areas of production, business management, the provision of services in medicine, the banking sector, and the social sphere. It is proved that comfortable life, the security of the processes through qualitatively new regulatory approaches, the state security, including cybersecurity, overcoming the adverse effects due to natural disasters, as well as the introduction of biotechnology, entailing the appearance of unknown infectious diseases and viruses, preventing man-made disasters - these and many other goals and objectives can't be achieved now or get a solution without the use of digital information technologies. It is also impossible to ignore the studies of the society and nature interaction, the cross-sectoral impact of modern technology in the field of renewable energy, the turnover of energy resources and energy efficiency improvement on the environment, the life and health of citizens, the public and state institutions designed to participate in the protection of the environment which corresponds to the solution of the specific objectives set in the Strategy for Scientific and Technological Development of the Russian Federation. According to the author, the studies of the dynamics of interaction between the economic and legal institutions in the field of renewable energy development, the turnover of energy resources, and energy efficiency improvement will contribute to the expansion in renewable energy as one of the "green" sectors of the economy.

Key words: industrial revolution, telecommunications technologies, Internet of things, wireless technologies, environment, human health, ecological system, ecological entrepreneurship, "green" sectors of the economy, energy resources, energy efficiency, renewable energy sources.

Citation. Inshakova A.O. Legal Adaptation in the Context of the Impact of the Industrial Revolution on Business Activity and the Key Components of the Ecosystem. Legal Concept = Pravovaya paradigma, 2021, vol. 20, no. 1, pp. 6-13. (in Russian). DOI: https://doi.org/10.15688/lc.jvolsu.2021.1.1
\end{abstract}


УДК $347: 346.26$

ББК 67.404 .91

\title{
Агнесса Олеговна Иншакова
}

Волгоградский государственный университет, г. Волгоград, Российская Федерация

\section{ПРАВОВАЯ АДАПТАЦИЯ В УСЛОВИЯХ ВЛИЯНИЯ ПРОМЫШЛЕННОЙ РЕВОЛЮЦИИ НА ПРЕДПРИНИМАТЕЛЬСКУЮ ДЕЯТЕЛЬНОСТЬ И КЛЮЧЕВЫЕ КОМПОНЕНТЫ ЭКОСИСТЕМЫ}

\begin{abstract}
Аннотация. Статья представляет собой обзор выбранных для главной темы номера тематик, их актуальности и обоснованности проведенных в журнале исследований для законодательства и правоприменительной практики в условиях промышленной революции и необходимости экологизации современного бизнеса. Кроме того, автор аргументирует выбор редакционной коллегии главной темы очередного номера юридического журнала Волгоградского государственного университета «Legal Concept $=$ Правовая парадигма» под названием «Право на страже здоровья человека и экологически чистой предпринимательской среды». Обосновывается объективная необходимость развития технологий интенсивного вовлечения потенциала российского экологического предпринимательства в процессы промышленной революции. Обозначены важнейшие задачи, на решение которых направлены разработки в сфере правового регулирования процессов цифровизации экологического предпринимательства в России. Перечисляется комплекс мер, которые, по мнению автора, являются первоочередным для обеспечения этих процессов. Отмечается, что предлагаемая к разработке тема тесно связана с формированием научных и технологических заделов, обеспечивающих экономический рост и социальное развитие Российской Федерации. Достигнутое современным обществом состояние научнотехнического прогресса проявляется широким использованием цифровых технологий в различных сферах производства, управления бизнесом, оказания услуг в медицине, банковском секторе, социальной сфере. Доказано, что комфортные условия жизни человека, защищенность процессов через качественно новые регулятивные подходы, обеспечение безопасности государства, в том числе кибербезопасности, преодоление неблагоприятных последствий вследствие природных катаклизмов, а также в результате внедрения биотехнологий, влекущих за собой появление неизученных инфекционных заболеваний и вирусов, предупреждение техногенных катастроф - эти и масса других целей и задач не могут ныне достигаться или получать решение без применения цифровых информационных технологий. Нельзя обойти вниманием и исследования взаимодействия общества и природы, межотраслевого воздействия современных технологий в сфере ВИЭ, оборота энергетических ресурсов и повышения энергоэффективности на состояние окружающей среды, жизнь и здоровье граждан, состояние общественных и государственных институтов, призванных участвовать в охране окружающей среды, соответствует решению конкретных задач, поставленных в Стратегии научно-технологического развития Российской Федерации. По мнению автора, исследования динамики взаимодействия экономических и правовых институтов в сфере развития ВИЭ, оборота энергетических ресурсов и повышения энергоэффективности будуг способствовать расширению ВИЭ как одного из «зеленых» секторов экономики.

Ключевые слова: промышленная революция, телекоммуникационные технологии, интернет вещей, беспроводные технологии, окружающая среда, здоровье человека, экологическая система, экологическое предпринимательство, «зеленые» секторы экономики, энергетические ресурсы, энергоэффективность, возобновляемые источники энергии.
\end{abstract}

Цитирование. Иншакова А. О. Правовая адаптация в условиях влияния промышленной революции на предпринимательскую деятельность и ключевые компоненты экосистемы // Legal Concept = Правовая парадигма. - 2021. - Т. 20, № 1. - С. 6-13. - DOI: https://doi.org/10.15688/lc.jvolsu.2021.1.1

В условиях промышленной революции развитие технологий интенсивного вовлечения потенциала российского экологического предпринимательства, а также теоретических понятий и концептуальных основ его правового регулирования является необходимым усло- вием, обеспечивающим устойчивый экономический рост Российской Федерации.

Актуальность выбранной темы обусловлена тем, что охрана окружающей среды не может быть эффективна только посредством мер, предпринимаемых органами публичной 
власти. Для достижения поставленной в Конституции РФ цели - обеспечения права каждого на благоприятную окружающую среду необходимо задействовать финансовый и творческий потенциал российского бизнеса, создать условия, при которых гражданам будут продаваться товары и оказываться услуги, не влияющие негативно на их здоровье и не разрушающие экосистемы, находящиеся в ряде регионов в критическом состоянии. В этой связи остро необходимо специальное экономико-правовое регулирование экологического предпринимательства, предусматривающее превентивно-профилактические механизмы нейтрализации возможных негативных воздействий индустриальной экономики и неоиндустриальные сквозные технологии развития низкоуглеродной, ресурсосберегающей и социально инклюзивной модели «зеленой» экономики». В России уже накоплен небольшой теоретический и практический опыт государственного стимулирования предпринимательской деятельности в области охраны окружающей среды, однако и научные исследования, и предоставление субсидий и льгот предпринимателям, внедряющим наилучшие доступные технологии, осуществляется достаточно бессистемно, отсутствует комплексный подход к пониманию приоритетных направлений взаимодействия государства и бизнеса. Не получили отражение в законодательстве и правоприменительной практике и средства противодействия новым экологическим угрозам, включая глобальное изменение климата, незначительность производства экологически чистой (органической) продукции, внедрения новых технологий производства электроэнергии из возобновляемых источников, новых способов переработки отходов и т. д. Также отсутствует правопорядок интенсивного внедрения и применения неоиндустриальных цифровых технологий, включая дистанционно-цифровые способы осуществления инвестиций, обеспечивающие ускоренное развитие «зеленой» экономики в современной России. В решении всех этих проблем в ряде зарубежных стран принимают активное участие экологические предприниматели, для которых созданы надлежащие условия работы. Данный опыт может представлять интерес и для России, с учетом особенностей ее правовой системы и состояния окружающей среды. Развитие системы экологического предпринимательства, выявление ее основных элементов и разработка мер государственной и частной инвестиционной поддержки, в том числе посредством института государственно-частного партнерства, позволит дать комплексный ответ на глобальные вызовы современности, улучшить состояние окружающей среды, сформировать на государственном уровне управленческий алгоритм применения сквозных технологий для расширения «зеленых» секторов экономики.

Исследования, представленные в главной теме очередного номера юридического журнала Волгоградского государственного университета «Legal Concept $=$ Правовая парадигма» под названием «Право на страже здоровья человека и экологически чистой предпринимательской среды», направлены на решение важнейших задач современной России, которые решаются посредством запущенных процессов цифровизации экологического предпринимательства. Комплекс мер, обеспечивающих эти процессы, включает: подготовку специализированных кадров; значительные финансовые затраты на обслуживание цифровых технологий; маркетинг экологически ориентированных предприятий и организаций, а также экологических товаров, работ и услуг; формирование экологической составляющей потребительских предпочтений; развитие «зеленой» экономики и «зеленых» инвестиций и финансовых инструментов, посредством которых осуществляется финансирование развития промышленности и сельскохозяйственных проектов. Предполагаемые результаты создадут условия для системного подхода к изменению вектора российской экономики в сторону экорынка и экобизнеса, определят перспективные направления совершенствования российской нормативно-правовой базы, которая в настоящее время практически отсутствует в области экологического предпринимательства на государственном уровне.

Глубокая проработка предлагаемой редакционной коллегией темы научного исследования должна привести к выявлению новых «точек соприкосновения» юриспруденции и экономики, определить перспективные направления осуществления инвестиций в сфере развития системы возобновляемых источников 
энергии, оборота энергетических ресурсов и повышения энергоэффективности, помочь спрогнозировать позитивный экономический эффект от внедрения новых экологически чистых технологий, создать условия для выполнения Российской Федерацией своих международных обязательств в области охраны окружающей среды. Предлагаемые решения должны быть направлены на создание условий и стимулов повышения энергоэффективности и обеспечения энергетической и экологической безопасности Российской Федерации. Полагаем, что полученные результаты должны обеспечить баланс частных и публичных интересов в сфере развития сектора возобновляемых источников энергии (ВИЭ), оборота энергетических ресурсов и повышения энергоэффективности, определить перспективные направления совершенствования российского законодательства. В современных условиях вопросам развития экологического предпринимательства и его отдельных элементов (экологический туризм, обращение с отходами, строительство экологических зданий и т. д.) уделено достаточно внимания в мировой и российской экономической науке, однако отсутствуют четкие механизмы реализации этих предложений, отсутствует понимание основных этапов процесса применения сквозных технологий для развития низкоуглеродной, ресурсосберегающей и социально инклюзивной модели «зеленой» экономики.

Предлагаемый проект тесно связан с формированием научных и технологических заделов, обеспечивающих экономический рост и социальное развитие Российской Федерации. Решение конкретных задач, поставленных в Стратегии научно-технологического развития Российской Федерации, предполагает сбор эмпирических данных о сложившейся ситуации в сфере взаимодействия общества и природы, межотраслевого исследования воздействия современных технологий в сфере ВИЭ, оборота энергетических ресурсов и повышения энергоэффективности на состояние окружающей среды, жизнь и здоровье граждан, состояние общественных и государственных институтов, призванных участвовать в охране окружающей среды. Исследования динамики взаимодействия экономических и правовых институтов в сфере развития ВИЭ, обо- рота энергетических ресурсов и повышения энергоэффективности будут способствовать расширению ВИЭ как одного из «зеленых» секторов экономики.

Достигнутое современным обществом состояние научно-технического прогресса проявляется широким использованием цифровых технологий в различных сферах производства, управления бизнесом, оказания услуг в медицине, банковском секторе, социальной сфере. Комфортные условия жизни человека, защищенность процессов через качественно новые регулятивные подходы, обеспечение безопасности государства, в том числе кибербезопасности, преодоление неблагоприятных последствий вследствие природных катаклизмов, а также в результате внедрения биотехнологий, влекущих за собой появление неизученных инфекционных заболеваний и вирусов, предупреждение техногенных катастроф - эти и масса других целей и задач не могут ныне достигаться или получать решение без применения цифровых информационных технологий. В данной связи широкий спектр вопросов развития и обеспечения цифровой инфраструктуры в различных сферах общественной жизнедеятельности не может остаться вне внимания: от технологий виртуальной реальности, создания инновационных структур, использующих, в частности, технологии дополненной реальности, кросс-отраслевых решений, механизмов управления и использования ресурсов, описания сквозных технологий, применяемых в целях контроля за трансграничным движением капитала как на мировом, так и на внутригосударственном уровне, новых технологий и новых механизмов коммуникации участников судебного процесса в судебную систему и т. д.

Конкурентными преимуществами и уникальностью такого рода разработок должны стать, прежде всего, изучение не самих технологий 4:0, а правового регулирования экологического предпринимательства и инноваций с применением этих технологий. В связи с этим необходима выработка комплексного подхода к исследованию правовых механизмов развития цифровых технологий в регулировании экологического предпринимательства. Теоретическая разработка стандартов межотраслевого взаимодействия позволит выстроить сбалансированную систему механизмов пра- 
вового регулирования всех сфер экологического предпринимательства, более адекватно отобразить в предложенных проектах федеральных законов основные элементы экономического стимулирования охраны окружающей среды и поддержки экологического и инновационного предпринимательства.

При формировании теоретической модели государственного регулирования и поддержки экологического предпринимательства в России, включающей механизмы и сквозные технологии обеспечения его вклада в сохранение и восстановление окружающей среды и охрану природных ресурсов в качестве первоочередных задач, должны выступать: выявление особенностей подготовки программных политико-правовых документов в области развития экологического предпринимательства, позволяющих найти баланс между экономическими, экологическими и социальными интересами граждан, бизнеса и государства; обоснование комплекса сквозных технологий по сохранению и восстановлению окружающей среды и охране природных ресурсов; определение наиболее эффективных неоиндустриальных технологий, включая дистанционно-цифровые способы осуществления инвестиций, обеспечивающих ускоренное развитие «зеленой» экономики в Российской Федерации; разработка нового организационного (управленческого) механизма государственной поддержки экологического предпринимательства в Российской Федерации и субъектах РФ; выявление приоритетных экономико-правовых механизмов инвестирования экологического предпринимательства посредством цифровых технологий в Российской Федерации и субъектах РФ; разработка Концепции развития правового регулирования «зеленой» экономики и определение перечня мер по ее государственной поддержке на федеральном и региональном уровнях; подготовка проекта федерального закона «О мерах государственной поддержки экологического предпринимательства».

Влияние промышленной революции на экосистему трудно переоценить. Популярность, широкое распространение и растущая зависимость от беспроводных технологий породили телекоммуникационную промышленную революцию, развитие интернета вещей (IoT), который обеспечивает нам более ком- фортный образ жизни с массивной взаимосвязанной телекоммуникационной сетью $5 \mathrm{G}$. Вместе с тем расширение широкополосной связи с помощью более коротковолнового радиочастотного излучения вызывают еще большую озабоченность ученых, связанную с вопросами здоровья человека и безопасности для окружающей среды. Еще не закончены споры относительно всех последствий, которые влекут за собой современные беспроводные технологии $2 \mathrm{G}, 3 \mathrm{G}$ и $4 \mathrm{G}$, еще не изучены до конца технологии, способные их нивелировать. Между тем уже приходится задумываться и о технологиях $5 \mathrm{G}$, которые еще гораздо менее изучены с точки зрения воздействия на человека или окружающую среду. Исследователи утверждают, что добавление дополнительного высокочастотного излучения $5 \mathrm{G}$ к уже сложному сочетанию более низких частот будет способствовать негативным последствиям для общественного здравоохранения как с точки зрения физического, так и психического здоровья человека [5]. Радиочастотное излучение также все чаще признается сильной, до конца неизученной формой загрязнения окружающей среды. Не только представителям технических наук необходимо задумываться о проблемах общественного здравоохранения при продвижении новых беспроводных технологий. Ученые отмечают, что пройдут годы или десятилетия, прежде чем станут известны истинные последствия для здоровья человека [5].

Если проанализировать негативные последствия различных влияний промышленной революции через предпринимательскую деятельность, то можно отметить серьезные изменения в различных ее отраслях. Так, информационные технологии во многом способствовали развитию туризма. Между тем мобильные терминалы и коммуникационные технологии в последние годы также полностью изменили и его бизнес-модель, и его структуру, в связи с чем возникли вполне закономерные негативные последствия для экологической среды. По мнению ученых, технологии, вызвавшие такие негативные последствия, могут способствовать и развитию мер по противодействию им. Например, сегодня широко обсуждаются меры противодействия негативным влияниям на экологическую среду на ос- 
нове больших данных. Однако уже понятно, что чрезмерно интенсивная деятельность по развитию туристических ресурсов нанесет непоправимый экологический ущерб. Таким образом, предлагается перед эксплуатацией и использованием туристических ресурсов анализировать и оценивать «выносливость» конкретной окружающей среды региона, чтобы минимизировать негативное воздействие на нее вследствие развития туризма [2]. Обеспечить юридическую обязательность выполнения и применения разработанных мер по соблюдению баланса между повышенными бизнес-эффектами и сохранением здоровой экосистемы призвано право.

Можно привести в пример и последствия, связанные с влиянием бизнес-среды на экологию и в сфере судоходной отрасли и повышением ее производительности в условиях современной мировой торговли. Морские перевозки подразумевают физическое перемещение грузов от мест производства к местам потребления. Хотя морские перевозки полезны для мировой торговли, а также для экономического развития стран, связанные с ними действия могут нанести вред окружающей среде, например, $\mathrm{CO}_{2}$, выбросы и сброс балластных вод. В результате растет обеспокоенность общественности по поводу экологического ущерба, причиняемого судоходством при обслуживании международной торговли. Чтобы сбалансировать защиту окружающей среды и повышение эффективности бизнеса, судоходным компаниям следует уделять больше внимания экологическим и финансовым последствиям своей деловой практики. Ученые работают над концепцией экологичности и относительности производительности (GPR), а также анализируют взаимосвязь мер по экологизации с производительностью компаний, участвующих в морских перевозках. Утверждается, что существует положительная связь между экологизацией и эффективностью деятельности компаний в сфере морских перевозок с применением новых технологий. Доказано, что судоходные компании обладают достаточно широкими возможностями благодаря технологиям Индустрии 4:0 [4].

В исследованиях приоритетов в деятельности предпринимательской среды, ори- ентированной на технологии Индустрии 4:0, была представлена аналитика мнений руководителей бизнес-лидеров. Так, пять руководителей торговых палат и десять руководителей бизнеса поделились своим мнением о том, какое значение они придают здоровью в своем бизнесе и в обществе в целом. В результате здоровье сотрудников было выделено как главный приоритет среди бизнес-лидеров. Многие руководители признали прямую роль здоровья в производительности и доходах их бизнеса [1]. По сравнению со здоровьем сотрудников, здоровье сообщества не было столь значительным для этих бизнеслидеров; однако они признают связь между здоровьем населения и экономическим развитием. Повышение участия бизнес-лидеров в улучшении здоровья населения потребует не только дополнительного образования и ресурсов, но и правовой регламентации этих процессов.

Вспышка эпидемии COVID-19 угрожает здоровью всех людей и требует безотлагательного внимания и активных ответных действий всех стран и всех слоев общества [3]. Ученые по всему миру все чаще задаются вопросом может ли право сыграть значительную роль в сдерживании пандемии и болезненного образа жизни? Может ли существовать жизнеспособный международно-правовой инструмент, который поддерживал бы целенаправленную политику по сдерживанию эпидемий [6]. Полагаем, такой инструмент необходимо активно продвигать и обсуждать с широким кругом заинтересованных сторон, ориентируясь на сложную международную структуру существующих норм и противоречивых, мощных интересов.

В рубрике «Главная тема номера» представлены научные исследования, посвященные: уголовно-правовой оценке общественно опасных последствий экологических преступлений; технически сложным товарам в контексте прав потребителя при обнаружении в них недостатков; законодательным новеллам предупреждения распространения коронавирусной инфекции в Российской Федерации; правовым механизмам обращения радиоактивных отходов и отработавшего ядерного топлива в праве ЕС; международно-правовым принципам охраны окружающей среды в 
применении к формированию международной природоохранной организации Каспийского моря.

Примечательно, что в представленном номере реализовано расширенное межвузовское сотрудничество 15 ведущих научных школ страны. В перечне вузов, с которыми аффилированы авторы номера: Российский государственный университет правосудия (Крымский филиал); Белгородский юридический институт МВД России им. И.Д. Путилина; Финансовый университет при Правительстве Российской Федерации (г. Москва); Донецкая академия внутренних дел (Министерство внутренних дел Донецкой Народной Республики); Ростовский государственный экономический университет; Московский государственный институт международных отношений (МГИМО МИД России); Российский университет дружбы народов (г. Москва); Байкальский государственный университет (г. Иркутск); Башкирский государственный университет (г. Уфа); Саратовская государственная юридическая академия; Российская академия народного хозяйства и государственной службы при Президенте Российской Федерации (Волгоградский филиал); Томский государственный университет; Уральский государственный юридический университет (г. Екатеринбург).

\section{СПИСОК ЛИТЕРАТУРЫ}

1. Business leaders' attitudes about value of employee and community health / M. Heffernan, M. Meit, M. Powers, B. C. Castrucci, K. Sellers // Journal of Public Health Management and Practice. 2020 (1 September). - Vol. 26, iss. 5. - P. 493-496.

2. Cheng, W. Research on the impact of tourism development on regional ecological environment and countermeasure based on big data / W. Cheng, Y. Zhang // Boletin Tecnico/Technical Bulletin. 2017. - Vol. 55, iss. 7. - P. 464-470.

3. Fang, G. Legislation advancement of one health in China in the context of the COVID-19 pandemic: From the perspective of the wild animal conservation law / G. Fang, Q. Song // One Health. 2021 (June). - Vol. 12.

4. Greening and performance relativity: An application in the shipping industry/Y. H. V. Lun, K.-H. Lai, C. W. Y. Wong, T. C. E. Cheng // Computers and Operations Research. - 2015 (February). Vol. 54. - P. 295-301.

5. Russell, C. L. 5G wireless telecommunications expansion: Public health and environmental implications / C. L. Russell // Environmental Research. 2018 (August). - Vol. 165. - P. 484-495.

6. Stoeva, P. International norm development and change: Can international law play ameaning ful role incurbing the life style disease pandemic? / P. Stoeva // BMC International Healthand Human Rights. - 2020 (23 July). - Vol. 20, iss. 1.

\section{REFERENCES}

1. Heffernan M., Meit M., Powers M., Castrucci B.C., Sellers K. Business Leaders' Attitudes About Value of Employee and Community Health. Journal of Public Health Management and Practice, 2020 (1 September), vol. 26, iss. 5, pp. 493-496.

2. Cheng W., Zhang Y. Research on the Impact of Tourism Development on Regional Ecological Environment and Countermeasure Based on Big Data. Boletin Tecnico/Technical Bulletin, 2017, vol. 55, iss. 7, pp. 464-470.

3. Fang G., Song Q. Legislation Advancement of one Health in China in the Context of the COVID-19 Pandemic: From the Perspective of the Wild Animal Conservation Law. One Health, 2021 (June), vol. 12.

4. Lun Y.H.V., LaiK.-H., Wong C.W.Y., Cheng T.C.E. Greening and Performance Relativity: An Application in the Shipping Industry. Computers and Operations Research, 2015 (February), vol. 54, pp. 295-301.

5. Russell C.L. 5G Wireless Telecommunications Expansion: Public Health and Environmental Implications. Environmental Research, 2018 (August), vol. 165 , pp. 484-495.

6. Stoeva P. International Norm Development and Change: Can International Law Play Ameaning Ful Role Incurbing the Life Style Disease Pandemic? BMC International Healthand Human Rights, 2020 (23 July), vol. 20, iss. 1. 


\section{Information About the Author}

Agnessa O. Inshakova, Doctor of Sciences (Jurisprudence), Professor, Head of the Department of Civil and International Private Law (Base Department of the Southern Scientific Centre of the Russian Academy of Sciences), Volgograd State University, Prosp. Universitetsky, 100, 400062 Volgograd, Russian Federation, gimchp@volsu.ru, https://orcid.org/0000-0001-8255-8160

\section{Информация об авторе}

Агнесса Олеговна Иншакова, доктор юридических наук, профессор, заведующая кафедрой гражданского и международного частного права (базовая кафедра ЮНЦ РАН), Волгоградский государственный университет, просп. Университетский, 100, 400062 г. Волгоград, Российская Федерация, gimchp@volsu.ru, https://orcid.org/0000-0001-8255-8160 